\title{
Supercritical carbon dioxide extraction of lipids from Eucalyptus globulus wood
}

\author{
F.J. González-Vila ${ }^{\mathrm{a}, *}$, J.M. Bautista ${ }^{\mathrm{a}}$, A. Gutiérrez ${ }^{\mathrm{a}}$, J.C. Del Rio ${ }^{\mathrm{a}}$, \\ A.G. González \\ ${ }^{a}$ Instituto de Recursos Naturales y Agrobiología, CSIC, P.O. Box 1052, E-41080 Sevilla, \\ Spain \\ ${ }^{\mathrm{b}}$ Department of Analytical Chemistry, University of Seville, E-41012 Sevilla, \\ Spain
}

\begin{abstract}
Various typical lipid components of wood extractives have been isolated from Eucalyptus globulus wood by supercritical carbon dioxide modified with methanol. The influence of various extraction parameters on the yield and qualitative composition of the extracts have been studied. The extracts were analyzed by gas chromatography-mass spectrometry and compared with those obtained by Soxhlet extraction with acetone, the standard method for the determination of wood extractives. The qualitative and quantitative results obtained by both methods were in good agreement. The experimental planning to asses the influence of pressure, temperature and percentage of methanol and their interactions on the extraction efficiency was carried out with a factorial design, followed by multiple linear regression algorithm. (C) 2000 Elsevier Science B.V. All rights reserved.
\end{abstract}

Keywords: Wood extractives; Eucalyptus globulus; Supercritical fluid-extraction; Modified $\mathrm{CO}_{2}$

\section{Introduction}

The accumulation of wood lipophilic extractives during pulping and papermaking (the so-called pitch deposits) cause significant technical and economic problems in pulp and paper manufacture [1]. The progressive introduction of more environmentally friendly bleaching processes is leading to an increase in pitch problems, and has consequently increased research devoted to the identification of wood extractives that may lead to pitch formation.

The standard method for the determination of wood extractives is based on Soxhlet extraction with acetone [2]. Due to the complexity of the lipid mixture in wood extractives, their analysis frequently involves an initial fractionation of samples into various lipid components that is too laborious and time-consuming for process studies, where a large number of samples need to be analyzed in a reasonable time.

Thus, it is of considerable interest to develop simple and rapid analytical procedures to monitor wood extractives previous to the pulping process in order to predict and control pitch problems. Thus, we have recently developed rapid procedures to determine the chemical composition of extractives from Eucalyptus globulus, the most economically important raw material for paper pulp production in Spain. They are based on the use of short high-temperature capillary columns with thin films, which allow rapid elution and separation of high-molecular mass lipid components without prior de- 
rivatization or fractionation $[3,4]$.

Supercritical fluid extraction (SFE) can be a valid alternative, since typical lipophilic wood and pulp extractives, such as fatty acids, resin acids, waxes, alcohols, terpenes, sterols, glycerides and sterol esters [5], can be extracted by supercritical carbon dioxide $\left(\mathrm{S}-\mathrm{CO}_{2}\right)$, as demonstrated by Jansson et al. [6] in the analyses of extractives from unbleached pine kraft pulp with $\mathrm{S}-\mathrm{CO}_{2}$. Likewise, resin and fatty acids were extracted from potentially toxic pulp mill sludges and sediments at pulp mill sites with modified $\mathrm{S}-\mathrm{CO}_{2}[7,8]$.

This work describes the optimization of the extraction of different classes of lipidic components from wood by $\mathrm{S}-\mathrm{CO}_{2}$ modified with methanol. The experimental planning to assess the influence of pressure, temperature and percentage of methanol and their interactions on the extraction efficiency was carried out with a factorial design, followed by multiple linear regression (MLR) algorithm [9].

The supercritical extracts were analyzed by gas chromatography (GC) and gas chromatography-mass spectrometry (GC/MS) and compared qualitatively with those previously obtained by conventional Soxhlet extraction $[3,4]$.

\section{Material and methods}

\section{Conventional extraction}

Replicated samples (20 g) of Eucalyptus globulus wood chips, ground to pass a 2-mm sieve, were exhaustively extracted with acetone in a Soxhlet apparatus for $24 \mathrm{~h}$. The extracts were evaporated to dryness and redissolved in chloroform for their analyses by $\mathrm{GC}$ and $\mathrm{GC}-\mathrm{MS}$.

\section{Supercritical fluid extraction}

Samples were extracted by using SFE / SFC-grade supercritical $\mathrm{CO}_{2}$ on a Carlo Erba SFC 300 Pump instrument, controlled by an external computer and refrigerated with a circulator assembly, DC3-K20 (Haake-Fisons), at 48C. The apparatus allows, for each experiment, to vary the composition of supercritical fluid (neat SF or mixed with 
modifiers) and/or pressure (gradient operations), but not the temperature. To maintain the pressure of the system, fused-silica capillary columns of $12 \mathrm{~cm}$ length (I.D. $50 \mathrm{~mm}$ ) have been used as restrictors. Both can be thermostated by a heated mobile block. The flow ranged between 500 and $2500 \mathrm{ml} / \mathrm{min}$, depending on the pressure.

The extraction thimble (Keystone Scientific $3.47 \mathrm{ml}$ ) was filled with $4 \mathrm{~g}$ of sample, and $0.4 \mathrm{~g}$ anhydrous sodium sulphate was added at the top as moisture absorber. A glass-fiber filter is fitted at both caps of the cell to minimize or avoid plugging of the restrictor. A static time that allows the fluid to diffuse through the sample is necessary. Extraction time of 30 min (static plus dynamic times) is enough if the flow is maintained above $500 \mathrm{ml} / \mathrm{min}$. Similar results were obtained when the wood sample was either spiked directly with the modifier prior to extraction or mixed with $\mathrm{S}-\mathrm{CO}_{2}$.

The extracts were collected in $2 \mathrm{ml}$ of methanol. Sublimation of $\mathrm{CO}_{2}$ decreases the temperature of the collection solvent, which acts as a freezing-trap. Thus, the loss of volatile compounds is minimized. All experiments were carried out in controlledpressure operation mode (COP) at pressures between $8 \mathrm{MPa}$ (target pressure) and 30 $\mathrm{MPa}$ (maximum pressure). The extraction was carried out in static mode for $10 \mathrm{~min}$ after an equilibrium time of $2 \mathrm{~min}$, followed by a 20-min dynamic extraction. The restrictor was heated to $708 \mathrm{C}$ by the heated mobile block.

\section{Gas chromatography-mass spectrometry}

All extracts were analyzed by GC (Hewlett-Packard 5890) and GC-MS (Varian Saturn 2000). A high-temperature capillary column (DB-5HT, $15 \mathrm{~m} 30.25 \mathrm{~mm}$ I.D., 0.1 mm film thickness; J\&W Scientific) was used with helium as the carrier gas. The oven was temperature-programmed from $1008 \mathrm{C}(1 \mathrm{~min})$ to $3508 \mathrm{C}(5 \mathrm{~min})$ at $158 \mathrm{C} / \mathrm{min}$. Compounds were identified by comparison with those stored in libraries (Wiley and Nist), and by mass fragmentography. Further details on the separation/identification conditions were previously published $[3,4]$.

\section{Results and discussion}

A reduced two-level full factorial experimental design for three factors was used to evaluate the significance of the considered variables. As we are interested in the study of the dependence of process yield on three factors, here $x_{1}, x_{2}$ and $x_{3}$ (representing percentage of methanol, pressure and temperature) $2^{3} 58$ runs must be performed. For each run, the involved levels for each factor are given in Table 1. Levels are coded according to the rule: high level 511 , low level 521 .

The eight runs, together with corresponding yields, are gathered in Table 2. This arrangement, easy to visualize, contains all the possible combinations among three factors at two levels. As two-level full factorial designs are saturated ones (the number of coefficients to be evaluated is the same as the number of required runs, unless replication is done) no error coefficient estimation is available, because there are no degrees of freedom in the regression. Thus, in Table 2, the yields corresponding to a 
Table 1

Values for the three variables in SFE

\begin{tabular}{|c|c|c|c|c|}
\hline \multirow[t]{2}{*}{ Factor } & \multicolumn{2}{|c|}{ Level 1 (low) } & \multicolumn{2}{|c|}{ Level 2 (high) } \\
\hline & Uncoded & Coded & Uncoded & Coded \\
\hline Percent methanol $\left(x_{1}\right)$ & 0 & 21 & 20 & 11 \\
\hline Pressure (Mpa) $\left(x_{2}\right)$ & 10 & 21 & 25 & 11 \\
\hline Temperature $(8 \mathrm{C})\left(x_{3}\right)$ & 40 & 21 & 75 & 11 \\
\hline
\end{tabular}

coded level 50 for every factor (center of design) have been included (average of three replicates) to have at least one degree of freedom (9-8 51).

Overall, the optimized extraction yields for SFE (calculated gravimetrically) were similar to or higher than by Soxhlet extraction with acetone $(1-2 \%)$. However, the yields shown in Table 2 correspond to the relative values calculated as total area response of the FID chromatograms from the extractives amenable to GC separation (chloroform soluble fraction).

The multiple linear regression (MLR) model equation for a two-level three-factor factorial design involving all main effects and interactions is:

$$
\text { Response } 5 b_{0} \mathbf{1} b_{1} x_{1} \mathbf{1} b_{2} x_{2} \mathbf{1} b_{3} x_{3} \mathbf{1} b_{12} x_{1} x_{2} \mathbf{1} b_{13} x_{1} x_{3} \quad \mathbf{1} b_{23} x_{2} x_{3} \mathbf{1} b_{123} x_{1} x_{2} x_{3}
$$

In our case, the MLR model equation is as follows (the coefficient values have been rounded to the last significant figure according to the standard deviations, which were ca. 0.2 in all cases):

Relative abundance (extract yields) $5 \begin{array}{llllllllllll}3.0 & 1 & 0.4 x_{1} & 2 & 0.4 x_{2} & 1 & 0.6 x_{3} & 1 & 0.1 x_{1} x_{2}\end{array}$

$$
10.1 x_{1} x_{3} 20.5 x_{2} x_{3} 20.1 x_{1} x_{2} x_{3}
$$

Table 2

Design matrix for three factors at two levels

\begin{tabular}{llllll}
\hline Run & $\begin{array}{l}x_{1} \\
\% \text { Methanol }\end{array}$ & $\begin{array}{l}x_{2} \\
\text { Pressure } \\
(\text { Mpa) }\end{array}$ & $\begin{array}{l}x_{3} \\
\text { Temperature } \\
(8 C)\end{array}$ & Density & $\begin{array}{l}\text { Relative } \\
\text { yields }^{\mathrm{a}}\end{array}$ \\
\hline 1 & $21(0)$ & $21(10)$ & $21(40)$ & 0.613 & 2.21 \\
2 & $1(20)$ & $21(10)$ & $21(40)$ & 0.613 & 2.32 \\
3 & $21(0)$ & $1(25)$ & $21(40)$ & 0.883 & 2.06 \\
4 & $1(20)$ & $1(25)$ & $21(40)$ & 0.883 & 3.05 \\
5 & $21(0)$ & $21(10)$ & $1(75)$ & 0.567 & 4.05 \\
6 & $1(20)$ & $21(10)$ & $1(75)$ & 0.567 & 5.15 \\
7 & $21(0)$ & $1(25)$ & $1(75)$ & 0.781 & 2.24 \\
8 & $1(20)$ & $1(25)$ & $1(75)$ & 0.781 & 3.39 \\
$9^{\text {b }}$ & $0(10)$ & $0(17.5)$ & $0(57.5)$ & 0.593 & 2.35 \\
\hline
\end{tabular}

${ }^{\text {a }}$ Calculated as total sum of areas in the gas chromatograms of the $\mathrm{CH}_{3} \mathrm{Cl}$-soluble extractives.

${ }^{b}$ The independent term represents the response (here the yield) at zero level of every factor, i.e., the

response at the center of the design. Average of three replicates. 


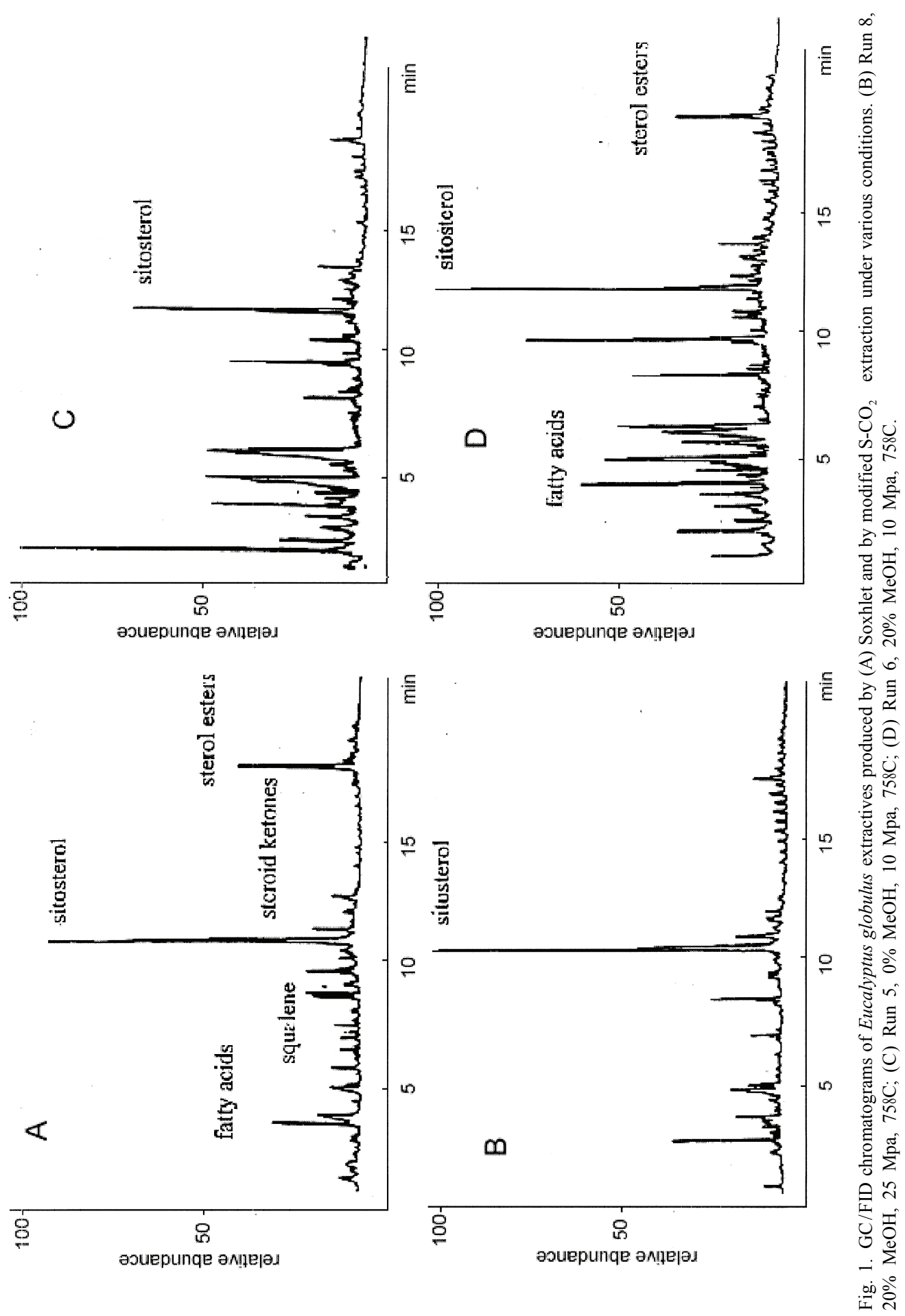


Use of the Student $t$-test for evaluating the significance of the regression coefficients shows that at least for a $P$ level of about 0.1 , the interactions $x_{1} x_{2}, x_{1} x_{3}$ and $x_{1} x_{2} x_{3}$ are non-significant and drop out from the model. By repeating the calculations (now with

9-554 degrees of freedom) we obtain (here, again the coefficient values have been rounded to the last significant figure according to the standard deviations, which were also ca 0.2 in all cases):

Relative abundance (extract yields) $5 \begin{array}{lllllllllllll}3.0 & 1 & 0.4 x_{1} & 2 & 0.4 x_{2} & 1 & 0.6 x_{3} & 2 & 0.5 x_{2} x_{3}\end{array}$

Note that the rounded coefficients are the same as in the complete MLR model, which ensures that the rejected terms do not contribute substantially to the build model.

Once the factors are normalized according the coding rule, the absolute value of the coefficient gives directly the importance of the considered factor. Thus, the results showed that temperature was the most important variable, followed by the addition of methanol, and pressure (the latter with a minus sign, indicating that higher yields will be obtained with lower pressures), as well as the presence of a significant interaction between pressure and temperature. Basically, the factor level combination $(1,21,1)$ (Run 6 of Table 2) gave the highest yield of extractives.

$\mathrm{S}-\mathrm{CO}_{2}$ with methanol was always more efficient than $\mathrm{S}-\mathrm{CO}_{2}$ without methanol. As previously suggested [6], methanol increases the extraction efficiency as a result of its interaction with the matrix, in this case the fibers, rather than a contribution to the solvent capacity of the $\mathrm{CO}_{2}$. A hydrophilic solvent is known to cause a swelling of the fibers, which may facilitate the removal of the extractives.

Higher pressure (higher $\mathrm{CO}_{2}$ density) somewhat improves the extraction yield, but at the same pressure the extraction yield improves with higher temperature (lower $\mathrm{CO}_{2}$ density). The positive effect of increased $\mathrm{T}$ might be an effect of decreased volatility of the extractives in a certain $\mathrm{T}$ region, which would enhance the extraction and thus counteract the effect of decreasing solvent density. A similar effect of $\mathrm{T}$ was found by Tilly et al. [10] in the extraction of triglycerides from vegetable oils.

The SFE extracts were analyzed by GC and GC/MS and compared with those obtained by Soxhlet extraction with acetone $[3,4]$. From the chromatograms presented in Fig. 1 it is apparent that the main classes of E. globulus extractives, such as fatty acids, sterols (sitosterol in particular) triglycerides and sterol esters were extracted by $\mathrm{CO}_{2}$ under supercritical conditions, the extracts being qualitatively similar to those obtained by Soxhlet extraction. The positive effect of increasing the addition of methanol (Run 6 versus Runs 6 or 8 ) is evidenced in Fig. 1 for the individual compounds, representing the different classes of Eucalyptus wood extractives. Although some triglycerides and sterol esters may be eluted closely, their differentiation is possible by GC/MS in the $15-\mathrm{m}$ column. Moreover, this is not a problem when the main purpose is to divide the extractives into chemical classes for monitoring, e.g., the extractive degradation produced by fungal activity.

\section{Simplified description of the method and and its applications}

We have demonstrated the applicability of off-line extraction with modified $\mathrm{S}-\mathrm{CO}_{2}$ as 
an attractive alternative to the conventional time-consuming and laborious solvent extraction of wood. For Eucalyptus globulus wood the yield and qualitative composition of wood extractives were similar to those obtained by the standard Soxhlet extraction with acetone.

The advantages of the method are all those derived from the well-known properties of supercritical fluids, including the short extraction time. It is therefore applicable to the characterization of wood extractives when many extractions must be performed in a reasonable time. This is necessary, e.g., when monitoring the efficiency of biotechnological or physicochemical solutions for the removal of the compounds responsible for pitch problems in pulp and paper manufacture.

\section{Acknowledgements}

This research has been supported by the projects PB95-0079 (Spanish CICYT) and FAIR CT95-0560 (UE-Commission).

\section{References}

[1] Hillis WE, Sumimoto M. Effects of extractives on pulping. In: Rowe JW, editor, Natural products of woody plants II, Berlin: Springer, 1989, pp. 880-920.

[2] Tappi T204 om-8

[3] Gutierrez A, Del Rio JC, González-Vila FJ, Martín F. Analysis of lipophilic extractives from wood and pitch deposits by solid-phase extraction and gas chromatography. J Chromatogr 1998;823:449-55.

[4] Gutierrez A, Del Rio JC, González-Vila FJ, Martín F. Chemical composition of lipophilic extractives from Eucalyptus globulus Labill. wood. Holzforschung 1999;53:481-6.

[5] Sjö strö m E. In: Wood chemistry. Fundamentals and applications, 2nd ed., San Diego, CA: Academic Press, 1993.

[6] Jansson MB, Alvarado F, Bergqvist AK, Dahlman O. Analysis of pulp extractives with off-line supercritical fluid extraction (SFE) and supercritical fluid chromatography (SFC). Proc Int Symp Wood Pulping Chem (Beijing) 1993;2:795-801.

[7] Lee HB, Peart T, Carron JM. Gas chromatographic and mass spectrometric determination of some resin and fatty acids in pulpmill effluents as their pentafluorobenzyl ester derivatives. $J$ Chromatogr 1990;498:367-71.

[8] Lee HB, Peart TE. Supercritical carbon dioxide extraction of resin and fatty acids from sediments and pulp mill sites. J Chromatogr 1992;594:309-15.

[9] González AG. Two level factorial experimental designs based on multiple linear regression models: a tutorial digest illustrated by case studies. Anal Chim Acta 1998;360:227-41.

[10] Tilly KD, Chaplin RP, Foster NR. Supercritical fluid extraction of the triglycerides present in vegetable oils. Sep Sci Techn 1990;25:357-9. 